\title{
Analisis Keseimbangan Air untuk Optimasi Pengembangan Komoditi Ramah Gambut
}

\author{
Widya Ayu Safitri ${ }^{1}$, Sigit Sutikno ${ }^{2}$, Rinaldi ${ }^{3}$ \\ 1,2,3 Program Studi S1 Teknik Sipil, Fakultas Teknik, Universitas Riau \\ Kampus Bina Widya J. HR Soebrantas KM 12,5 Pekanbaru, Kode Pos 28293 \\ Email: widya.ayusafitri@student.unri.ac.id, sigit.sutikno@lecturer.unri.ac.id, ri.naldi@eng.unri.ac.id
}

\begin{abstract}
ABSTRAK
Pada Kabupaten Siak terdapat lahan gambut Tamah Objek Reforma Agraria (TORA) seluas 10.000 ha berasal dari pelepasan Hak Guna Usaha PT.Makarya Eka Guna telah dibagikan 2.000 ha terdapat pada HGU 09 yang dikelola oleh pemerintah. Berdasarkan data dari Badan Restorasi Gambut sebagian besar lahan TORA berada pada kawasan gambut. Oleh sebab itu, optimasi lahan gambut seluas 2.000 ha yang akan dimanfaatkan untuk komoditi ramah gambut berdasarkan keseimbangan air dengan menjaga tinggi muka air kebutuhan pembasahan tetap $0,4 \mathrm{~m}$ di bawah permukaan tanah sesuai dengan regulasi pemerintah. Fluktuasi muka air tanah diprediksi dengan menggunakan metode regresi linier. Hasil penelitian menunjukkan bahwa analisis regresi dengan panjang data 2 bulan memberikan hasil prediksi muka air tanah yang terbaik dengan nilai koefisien korelasi 0,942. Pada hasil keseimbangan air alternatif komoditi padi sawah tadah hujan, jagung, nenas, ubi kayu, sagu, kelapa, pinang, aren, dan kopi dapat hidup sesuai dengan regulasi pemerintah jika ditanam pada bulan surplus yaitu pada periode bulan Februari, Maret, April, Oktober, dan Desember. Oleh karena itu, pada penelitian ini direkomendasikan manajemen pengelolaan air dengan sekat kanal untuk menjaga tinggi muka air tanah berada pada 0,4m di bawah permukaan tanah agar komoditi ramah gambut dapat tumbuh pada bulan defisit air di lokasi HGU 09.
\end{abstract}

Kata Kunci: lahan gambut, komoditas ramah gambut, keseimbangan air, tinggi muka air tanah

\begin{abstract}
In Siak Regency there is a 10,000 ha Tamah Peatland Agrarian Reform (TORA) peatland derived from the release of PT. Makarya Eka Guna's Cultivation Rights. 2,000 ha have been distributed in the HGU 09 managed by the government. Based on data from the Peat Restoration Agency, most of the TORA lands are in peat areas. Therefore, the optimization of 2,000 ha of peatlands that will be used for peat-friendly commodities based on water balance by maintaining the water level of wetting needs remains $0.4 \mathrm{~m}$ below the surface in accordance with government regulations. Groundwater level fluctuations are predicted using the linear regression method. The results showed that the regression analysis with a data length of 2 months gave the best predictive results for the ground water level with a correlation coefficient of 0.942 . In the alternative water balance results of rainfed lowland rice, corn, pineapple, cassava, sago, coconut, areca nut, sugar palm, and coffee can live according to government regulations if planted in surplus months, namely in the period of February, March, April, October, and December. Therefore, in this study it is recommended that water management with canal blocking to maintain ground water level is $0.4 \mathrm{~m}$ below the surface so that peat-friendly commodities can grow in the month of water deficit at the $H G U 09$ location.
\end{abstract}

Keywords: peatlands, peat-friendly commodities, water balance, ground water level

\section{PENDAHULUAN}

Gambut merupakan lahan basah yang terbentuk dari timbunan material organik yang berasal dari akumulasi sisa-sisa pohon, rerumputan, lumut dan jasad hewan yang membusuk. Tanah gambut memiliki sifat tergolong tanah yang rentan terhadap gangguan apabila gambut mendapat gangguan eksternal terutama akibat kemarau dan drainase yang berlebihan. Keadaan ini akan memudahkan terjadinya titik api di lahan gambut pada musim kemarau, serta imbasnya akan terjadinya penurunan tanah karena terjadinya kebakaran ground fire. Selain itu, dampak lain akan menimbulkan emisi $\mathrm{CO}_{2}$.
Titik api, penurunan tanah dan emisi $\mathrm{CO}_{2}$ merupakan beberapa dampak negatif dari pengelolaan lahan gambut akibat dari aktivitas dan kelalaian manusia. Selain itu, tanah gambut juga memiliki manfaat yaitu digunakan dalam proses peremajaan hutan, menambah lahan pertanian serta perkebunan dan meningkatkan hasil produksi pertanian.

Dampak negatif dari pengelolaan lahan gambut akibat dari aktivitas dan kelalaian manusia dapat direstorasi. Upaya restorasi gambut untuk mengembalikan fungsi ekologi lahan gambut dan kesejahteraan rakyat oleh Badan Restorasi Gambut (BRG) melalui pendekatan 3R yaitu rewetting, revegetasi dan revitalisasi. Revitalisasi ini 
adalah salah satunya adalah menambah mata pencaharian dan pendapatan masyarakat sekitar yaitu dengan mengembangkan lahan gambut.

Pada Kabupaten Siak terdapat lahan gambut TORA (Tanah Objek Reforma Agraria). Menurut Peraturan [3] lahan TORA adalah tanah yang dikuasai oleh negara atau tanah yang telah dimiliki oleh masyarakat untuk diredistribusi atau dilegalisasi. Lahan TORA di Kabupaten Siak seluas 10.000 ha berasal dari pelepasan Hak Guna Usaha (HGU) PT Makarya Eka Guna yang dikelola oleh pemerintah. Lahan TORA seluas 10.000 ha telah dibagikan 2.000 ha yang terdapat pada HGU 09 yaitu pada Kecamatan Mempura di Desa Koto Ringin dan Kecamatan Pusako di Desa Sungai Limau, Desa Sungai Berbari dan Desa Benayah. Lahan gambut TORA seluas 2.000 ha tersebut yang telah bersertifikat dan dibagikan kepada masyarakat yaitu masing-masing mendapatkan 0,8 ha.

Berdasarkan data dari Badan Restorasi Gambut lebih dari 50 persen luas lahan di Kabupaten Siak adalah lahan gambut dan sebagian besar lahan TORA berada pada kawasan gambut. Oleh sebab itu, 2.000 ha lahan TORA di HGU 09, Kabupaten Siak yang akan dikelola berbasis komoditi yang ramah gambut agar lahan gambut dapat dimanfaatkan dengan baik dan tidak merusaknya. Namun, untuk mendukung penanaman komoditi ramah lingkungan diatur dalam [2] bahwa ekosistem gambut dengan fungsi budidaya dinyatakan rusak apabila muka air tanah di lahan gambut lebih dari 0,4 meter di bawah permukaan gambut pada titik penaatan. Muka air tanah dijaga 0,4 meter ini adalah salah satu upaya untuk menjaga gambut agar selalu dalam kondisi basah. Hal ini berkaitan pada pemilihan komoditi yang bisa tumbuh baik pada kondisi tersebut. Pada lahan TORA HGU 09 pemilihan komoditi juga akan berpengaruh pada besarnya evapotranspirasi atau evaporasi yang bisa menyebabkan penurunan muka air tanah dan losses.

Penelitian ini akan melakukan analisis keseimbangan yaitu fluktuasi muka air tanah dan kebutuhan untuk pembasahan. Fluktuasi muka air tanah akan diprediksi dengan menggunakan metode regresi yaitu menggunakan data historis hujan dan data tinggi muka air tanah. Penelitian ini dilakukan sebagai pertimbangan untuk mendukung upaya optimalisasi pemilihan komoditi lahan gambut TORA pada HGU 09 di Kabupaten Siak.

\section{METODE PENELITIAN}

\section{Lokasi Penelitian}

Penelitian ini dilakukan pada lahan TORA HGU 09 yaitu pada Kecamatan Mempura di Desa Koto Ringin dan Kecamatan Pusako di Desa Sungai Limau, Desa Sungai Berbari dan Desa Benayah, Kabupaten Siak. Luas daerah TORA (Tanah Objek Reforma Agraria) pada HGU 09 adalah seluas 2000 ha, dapat dilihat pada Gambar 1 dan Gambar 2.

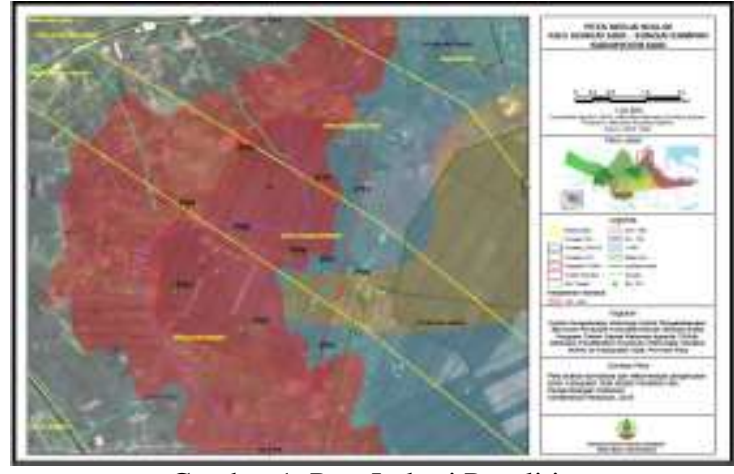

Gambar 1. Peta Lokasi Penelitian Sumber : Badan Restorasi Gambut (2018)

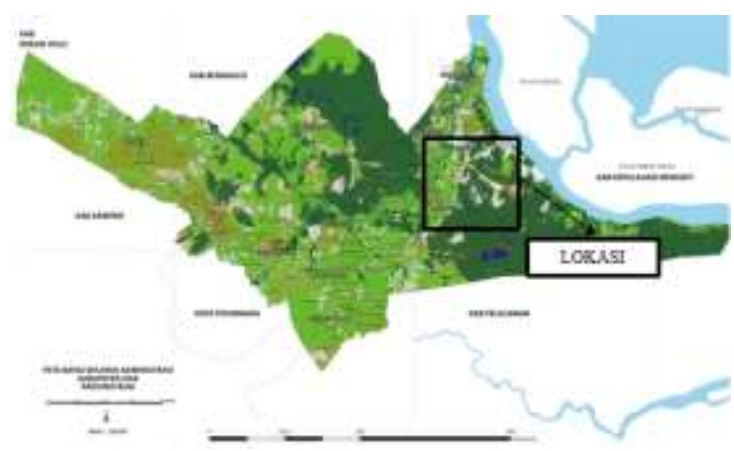

Gambar 2. Peta Daerah Kabupaten Siak

Sumber : Pemerintah Kabupaten Siak (2018)

\section{Data Penelitian}

Data-data yang diperlukan dalam penelitian adalah berupa data-data sekunder meliputi :

1. Data klimatologi

2. Data hidrologi

3. Peta dasar penelitian

\section{Prosedur Penelitian}

Prosedur penelitian ini adalah sebagai berikut:

1. Mempelajari literatur merupakan tahapan mencari referensi yang berhubungan dengan topik penelitian.

2. Mengumpulkan data. Data yang digunakan pada penelitian ini adalah data sekunder. Proses pengumpulan data dilakukan dengan cara mengambil data data dari instansi dan website terkait.

3. Menghitung evapotranspirasi.

4. Menghitung kebutuhan air tanaman.

Berdasarkan hasil studi yang telah dilakukan oleh tim peneliti gabungan yang terdiri dari Badan Restorasi Gambut (BRG), Sedagho Siak, PSB Universitas Riau, BPTP Provinsi Riau, dan Balai LHK Palembang maka merekomendasikan tanaman-tanaman yang potensial bisa ditanami di lahan gambut khususnya dilahan TORA adalah sebagai berikut:

1) Tanaman pertanian: padi sawah tadah hujan, jagung, nenas, dan ubi kayu; 
2) Tanaman perkebunan: sagu, kelapa, pinang, aren, dan kopi;

Jenis-jenis komoditi tersebut dapat tumbuh di lahan gambut dan terdapat pada lokasi TORA.

5. Menganalisis pemodelan data yaitu dengan menganalisis regresi, menganalisis muka air tanah dan validasi pemodelan data.

6. Menganalisis keseimbangan air.

\section{Bagan Alir Penelitian}

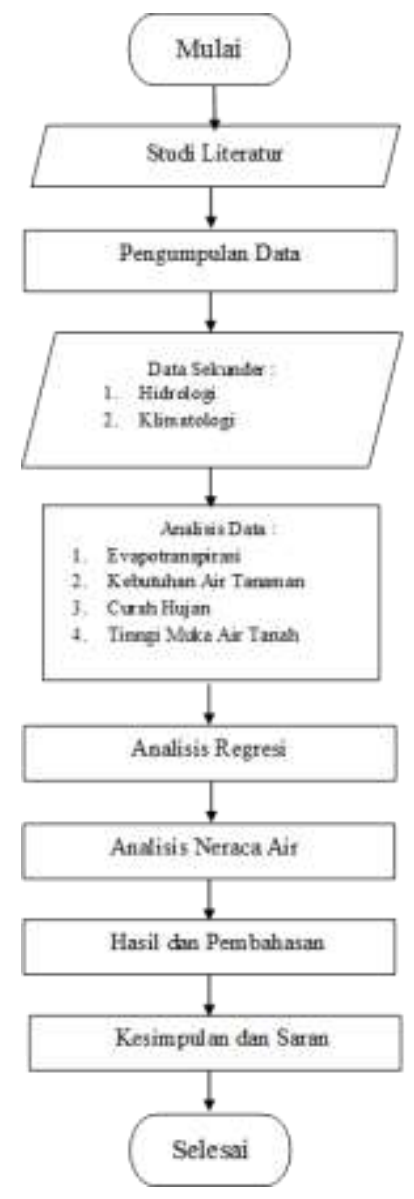

\section{HASIL DAN PEMBAHASAN}

\section{Analisis Evapotranspirasi}

Evapotranspirasi

merupakan

proses

menguapnya air pada lahan, permukaan air, dan tumbuhan yang disebabkan oleh faktor-faktor tertentu. Pengolahan data berdasarkan acuan dengan Metode Penman Modifikasi adalah sebagai berikut : Eto $=C^{*}(\mathrm{~W}(0,80 \mathrm{Rns}-\mathrm{Rn} 1)+(1-\mathrm{W}) * \mathrm{f}(\mathrm{u}) *(\mathrm{ea}-\mathrm{ed}))$

keterangan :

$$
\begin{aligned}
\mathrm{W}= & \text { faktor yang berhubungan dengan } \\
& \text { suhu dan elevasi } \\
\mathrm{Ra} \quad= & \text { radiasi gelombang pendek yang } \\
& \text { memenuhi batas luar atmosfir }
\end{aligned}
$$

atau angka angot ( $\mathrm{mm} / \mathrm{hari})$

Rs = radiasi gelombang pendek, dalam satuan evaporasi ekivalen (mm/hari)

Rn1 = radiasi bersih gelombang panjang (mm/hari)

$\mathrm{f}(\mathrm{U}) \quad=$ fungsi kecepatan angin pada

ketinggian 2 meter $(\mathrm{km} / \mathrm{hari})$

$\mathrm{f}(\mathrm{t}) \quad=$ fungsi suhu

$\mathrm{f}(\mathrm{n} / \mathrm{N})=$ fungsi kecerahan

$\mathrm{f}(\mathrm{ed}) \quad=$ fungsi tekanan uap

$\mathrm{RH}=$ kelembaban udara relatif $(\%)$

ea $\quad=$ tekanan uap sebenarnya yang besarnya berhubungan $t$

c $\quad=$ Faktor kofisien bulanan persamaan Penman dengan modifikasi

Hasil perhitungan besarnya nilai evapotranspirasi potensial dapat dilihat pada Tabel 1.

Tabel 1. Hasil Perhitungan Nilai Evapotranspirasi

Bulan Eto (mm/hari) Eto (mm/bulan)

\begin{tabular}{ccc}
\hline Jan & 3,75 & 116,163 \\
Feb & 4,04 & 113,050 \\
Mar & 3,32 & 103,031 \\
Apr & 2,88 & 86,448 \\
Mei & 2,81 & 87,199 \\
Jun & 2,71 & 81,229 \\
Jul & 2,70 & 83,736 \\
Ags & 3,63 & 109,013 \\
Sep & 3,70 & 110,917 \\
Okt & 3,25 & 100,620 \\
Nov & 3,39 & 101,834 \\
Des & 3,59 & 111,382 \\
\hline
\end{tabular}

\section{Analisis Kebutuhan Air Tanaman}

Kebutuhan air tanaman adalah kedalaman air yang diperlukan untuk memenuhi evapotranspirasi tanaman. ETcrop dapat didekati dengan persamaan sebagai berikut [4] :

ETcrop $=K c \times$ ETo

keterangan :

ETcrop = Kebutuhan air tanaman (mm/hari)

ETo = Evapotranspirasi $(\mathrm{mm} / \mathrm{hari})$

$\mathrm{Kc} \quad$ = Koefisien tanaman

Nilai kc (koefisien tanaman) berkisar antara 0,2 sampai 1,3. Oleh karena itu, nilai koefisien tanaman digunakan untuk tanaman pertanian adalah 1,1 dan 
tanaman perkebunan adalah 1,3 dengan pendekatan hujan tahunan.

Hasil perhitungan besarnya nilai kebutuhan air tanaman dapat dilihat pada Tabel 2 dan Tabel 3.

Tabel 2. Nilai Kebutuhan Air Tanaman untuk Tanaman Pertanian

\begin{tabular}{lccc}
\hline & \multicolumn{3}{c}{ Keterangan } \\
\cline { 2 - 4 } Bulan & Eto (mm) & Kc & Etc (mm) \\
\hline Jan & 116,163 & 1,1 & 127,779 \\
Feb & 113,050 & 1,1 & 124,355 \\
Mar & 103,031 & 1,1 & 113,334 \\
Apr & 86,448 & 1,1 & 95,093 \\
Mei & 87,199 & 1,1 & 95,919 \\
Jun & 81,229 & 1,1 & 89,352 \\
Jul & 83,736 & 1,1 & 92,110 \\
Ags & 109,013 & 1,1 & 119,914 \\
Sep & 110,917 & 1,1 & 122,008 \\
Okt & 100,620 & 1,1 & 110,682 \\
Nov & 101,834 & 1,1 & 112,017 \\
Des & 111,382 & 1,1 & 122,520 \\
\hline
\end{tabular}

Tabel 3. Nilai Kebutuhan Air Tanaman untuk Tanaman Perkebunan

\begin{tabular}{lccc}
\hline & \multicolumn{3}{c}{ Keterangan } \\
\cline { 2 - 4 } Bulan & Eto (mm) & Kc & Etc (mm) \\
\hline Jan & 116,163 & 1,3 & 151,011 \\
Feb & 113,050 & 1,3 & 146,965 \\
Mar & 103,031 & 1,3 & 133,940 \\
Apr & 86,448 & 1,3 & 112,383 \\
Mei & 87,199 & 1,3 & 113,359 \\
Jun & 81,229 & 1,3 & 105,598 \\
Jul & 83,736 & 1,3 & 108,857 \\
Ags & 109,013 & 1,3 & 141,717 \\
Sep & 110,917 & 1,3 & 144,192 \\
Okt & 100,620 & 1,3 & 130,806 \\
Nov & 101,834 & 1,3 & 132,384 \\
Des & 111,382 & 1,3 & 144,797 \\
\hline
\end{tabular}

\section{Analisis Curah Hujan}

Hasil perhitungan data curah hujan dari alat SESAME pada stasiun Kampung Rempak pada bulan Okrober 2018 sampai Juni 2019 yang telah diolah dari data persepuluh menitan menjadi data harian kemudian menjadi data bulanan terdapat pada Tabel 4 .
Tabel 4. Nilai Curah Hujan Bulanan di Kawasan TORA HGU 09 pada Oktober 2018- Mei 2019

\begin{tabular}{cc}
\hline Bulan & $\begin{array}{c}\text { Curah Hujan } \\
\text { (mm/bulan) }\end{array}$ \\
\hline Okt & 162,2 \\
Nop & 171,6 \\
Des & 158,4 \\
Jan & 19,2 \\
Feb & 37,6 \\
Mar & 94,2 \\
Apr & 91,8 \\
Mei & 4,6 \\
Jun & 10 \\
\hline
\end{tabular}

Data curah hujan bulanan yang akan digunakan untuk identifikasi neraca air ini memiliki kisaran nilai 4,6 $\mathrm{mm} / \mathrm{bulan}-171,6 \mathrm{~mm} / \mathrm{bulan}$.

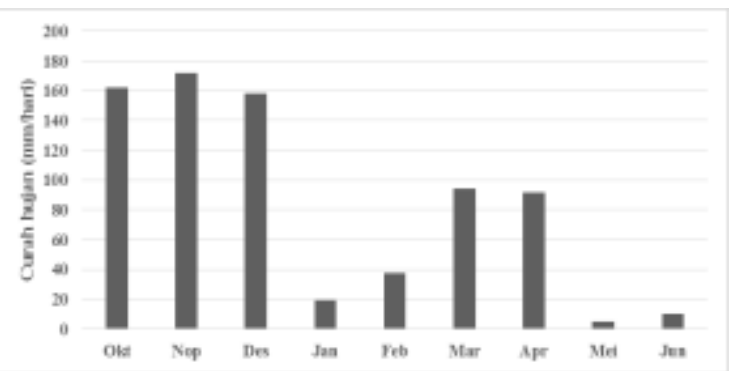

Gambar 3. Nilai Curah Hujan Bulanan di Kawasan TORA HGU 09 pada Oktober 2018- Mei 2019

Pada Gambar 3. dapat dilihat bahwa curah hujan maksimum terjadi pada bulan Oktober - November Desember dan pada bulan Januari hingga Juni terjadi penurunan intensitaas curah hujan yang tajam dari bulan Oktober-November-Desember.

\section{Analisis Muka Air Tanah}

Hasil perhitungan data muka air dari alat SESAME pada stasiun Kampung Rempak tanah pada bulan Okrober 2018 sampai Juni 2019 setelah dikurangkan dengan nilai offset yaitu sebesar $230 \mathrm{~cm}$ terdapat pada Tabel 6 .

Tabel 5. Tinggi Muka Air Tanah di Kawasan TORA HGU 09 pada Oktober 2018- Mei 2019

\begin{tabular}{cc}
\hline Bulan & Curah Hujan (mm/hari) \\
\hline Okt & $-0,721$ \\
Nop & $-0,821$ \\
Des & $-0,806$ \\
Jan & $-1,100$ \\
Feb & $-1,188$ \\
Mar & $-1,124$ \\
Apr & $-0,994$ \\
Mei & $-1,165$ \\
Jun & $-1,289$ \\
\hline
\end{tabular}


Data tinggi muka air tanah pada bulan juni memiliki tinggi muka air tanah terendah yaitu sebesar -1,289 m pada bulan Juni.

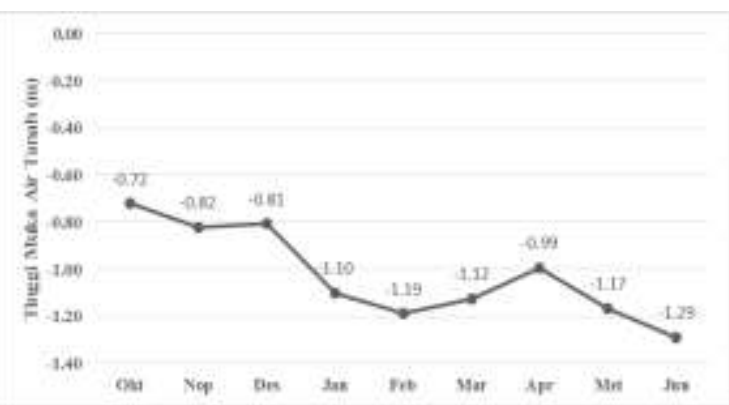

Gambar 4. Tinggi Muka Air Tanah di Kawasan TORA HGU 09 pada Oktober 2018- Mei 2019

Pada Gambar 4. dapat dilihat data tinggi muka air tanah bulan Oktober 2018 sampai Mei 2019. Pada gambar tersebut dapat dilihat tinggi muka air tanah relatif lebih tinggi pada bulan Oktober 2018 sampai Desember 2019. Selanjutnya, pada Januari 2019 sampai Juni 2019 tinggi muka air tanah relatif lebih rendah hingga mencapai 1,289 m pada Juni 2019.

\section{Analisis Permodelan Data}

Model hidrologi merupakan gambaran sederhana dari suatu sistem hidrologi yang aktual. Siklus hidrologi adalah aspek penting yang diperlukan untuk model hidrologi. Penggunaan model digunakan untuk memahami suatu sistem yang rumit agar menjadi lebih sederhana dibandingkan keadaan sebenarnya.

Kedalaman muka air tanah di lahan gambut sangat penting untuk pengelolaan dan pencegahan kebakaran lahan gambut. Oleh karena itu, prediksi muka air tanah di lahan gambut sangat penting untuk dilakukan.

Pada penelitian terdahulu telah dilakukan oleh [5] prediksi muka air tanah di lahan gambut bisa dilakukan dengan pemodelan matematis dapat dilihat pada persamaan berikut :

$d W=d W_{\text {rain }}-d W_{\text {logs }}$

keterangan :

$\begin{aligned} \mathrm{dW} & =\text { perubahan permukaan air tanah } \\ & \text { setiap hari } \\ \mathrm{dw}_{\text {rain }}= & \text { peningkatan harian tingkat } \\ & \text { muka air tanah oleh curah hujan } \\ \mathrm{dW} W_{\text {loss }}= & \text { kehilangan harian tingkat air } \\ & \text { tanah dengan evapotranspirasi } \\ & \text { dan limpasan. }\end{aligned}$

Parameter dWloss dan dWrain adalah suatu korelasi yang merupakan fungsi dari masing-masing evapotranspirasi dan hujan. Oleh karena itu, muka air tanah pada hari berikutnya bisa diperkirakan dengan menggunakan persamaan berikut ini :

$W_{n+1}=W_{n}+d W_{\text {rain }}-d W_{\text {loss }}$ keterangan :

$W_{n+1} \quad=$ ketinggian muka air tanah hari berikutnya

$\mathbf{W}_{\mathrm{n}} \quad=$ ketinggian muka air saat ini

\section{Analisis Regresi}

Analisis regresi dilakukan untuk mendapatkan suatu persamaan serta garis yang menunjukkan persamaan hubungan antara dua variabel. Menurut [1] untuk menunjukkan hubungan antara dua variabel dapat berupa data bivariat yang berbentuk titik-titik dan angka. Pada skenario analisis regresi tersebut didapatkan sebuah persamaan dan nilai koefisien determinasi $\left(\mathrm{R}^{2}\right)$ untuk $d W_{\text {rain }}$ dan $d W_{\text {loss. }}$ Data dipilih berdasarkan skenario yang memiliki nilai $\mathrm{R}^{2} d W_{\text {rain }}$ yang paling bagus pada setiap permodelan.

Permodelan data yang memiliki nilai $\mathrm{R}^{2} d W_{\text {rain }}$ yang paling bagus dengan metode analisis regresi adalah skenario panjang data 2 bulan yaitu bulan Januari 2019 sampai Februari 2019 yang dapat dilihat pada Gambar 5 sampai Gambar 6.

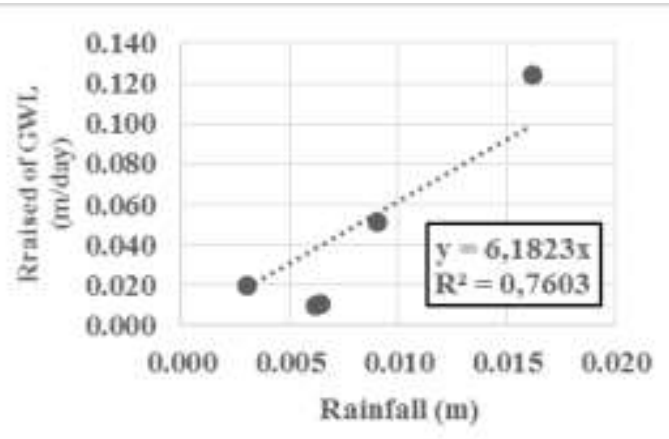

Gambar 5. Peningkatan Harian Muka Air Tanah oleh Curah Hujan Skenario Panjang Data 2 Bulan

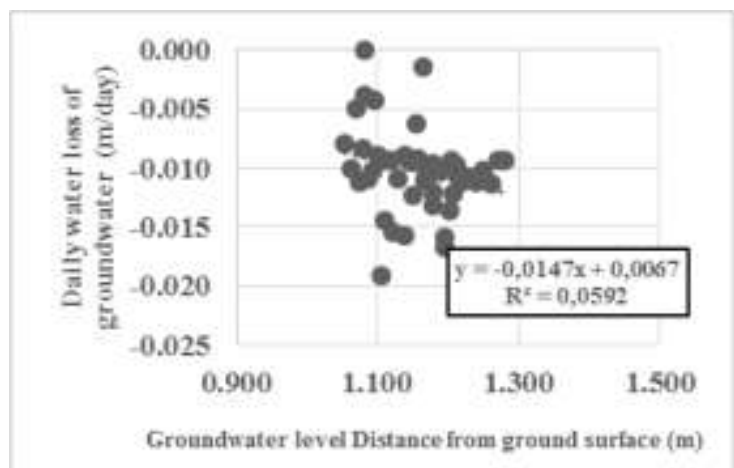

Gambar 6. Penurunan Harian Muka Air Tanah oleh Curah Hujan Skenario Panjang Data 2 Bulan

\section{Korelasi Hujan dan Fluktuasi Muka Air Tanah}

Evaluasi ketelitian model hidrologi dievaluasi menggunakan indikator koefisien korelasi (R) yang nilainya akan menunjukkan kuat atau tidaknya hubungan linear antara dua variabel dan untuk mengetahui sejauh mana data penelitian mendekati 
hasil data yang tepat dan akurat. Adapun kasifikasi besaraan nilai koefisien korelasi (R) dapat dilihat pada Tabel 6.

Tabel 6. Kriteria nilai koefisien korelasi

\begin{tabular}{cc}
\hline $\begin{array}{c}\text { Nilai Koefisien Korelasi } \\
|\mathrm{R}|\end{array}$ & Kriteria Hubungan \\
\hline 0,0 & Tidak ada korelasi \\
$0,0-0,5$ & Korelasi lemah \\
$0,5-0,8$ & Korelasi sedang \\
$0,8-1,0$ & Korelasi kuat \\
1,0 & Korelasi sempurna \\
\hline
\end{tabular}

Sumber : Sugiarto (2006)

Analisis perubahan tinggi muka air tanah harian $d W_{\text {rain }}$ dan $d W_{\text {loss }}$ dapat diperoleh menggunakan persamaan yang didapatkan berdasarkan analisis metode regresi. Analisis regresi tersebut menggunakan data skenario yang memiliki nilai $\mathrm{R}^{2} d W_{\text {rain }}$ yang paling bagus.

Hasil analisis regresi antara besaran hujan dan kenaikan muka air tanah menunjukkan korelasi yang tertinggi untuk panjang data 2 bulan (Januari 2019 Februari 2019) dengan nilai koefisien determinasi $\left(\mathrm{R}^{2}\right)$ yaitu 0,7603 yaitu korelasi 0,8719 yang artinya korelasi kuat.

\section{Prediksi Fluktuasi Muka Air Tanah}

Prediksi fluktuasi muka air tanah dilakukan dengan menggunakan persamaan regresi berdasarkan hasil analisis regresi antara besaran hujan terhadap kenaikan muka air tanah $\left(d W_{\text {rain }}\right)$ dan antara kedalaman muka air tanah dengan kehilangan air tanah $\left(d W_{\text {loss }}\right)$ sesuai dengan persamaan yang diperoleh dari analisis regresi.bPada prediksi fluktuasi muka air tanah ini diambil dari nilai dipilih yaitu memiliki nilai $\mathrm{R}^{2} d W_{\text {rain }}$ yang paling bagus yaitu pada skenario panjang data 2 bulan dengan nilai koefisien determinasi $\left(\mathrm{R}^{2}\right)$ 0,7603.

Grafik hasil prediksi fluktuasi muka air dibandingkan dengan nilai fluktuasi muka air tanah terukur untuk permodelan dapat dilihat pada Gambar 7.

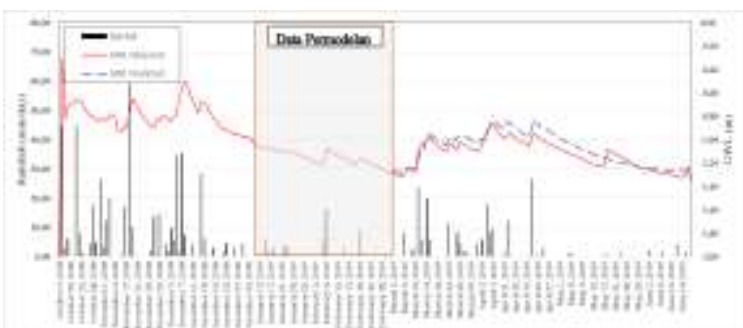

Gambar 7. Perbandingan Fluktuasi Muka Air Tanah Hasil Prediksi dengan Data Terukur untuk Panjang Data 2 Bulan
Setelah nilai $d W_{\text {rain }}$ dan $d W_{\text {loss }}$ diperoleh dengan nilai korelasi yang kuat maka langkah selanjutnya adalah menggunakan persamaan tersebut untuk memprediksi tinggi muka air tanah menggunakan data stasiun Buatan. Hasil dari prediksi tinggi muka air tanah stasiun Buatan pada tahun 2010 periode 1 tahun dapat dilihat pada Gambar 8 .

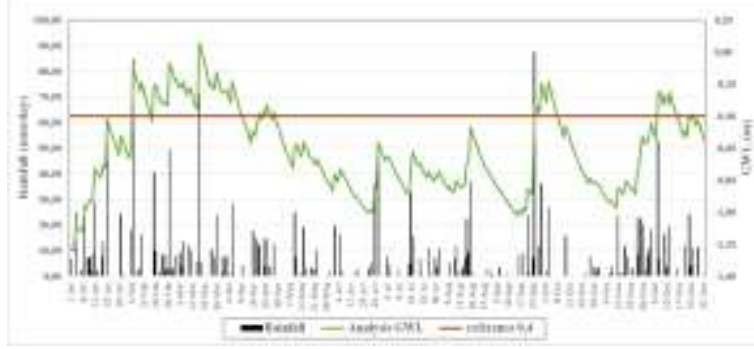

Gambar 8. Prediksi Tinggi Muka Air Tanah Data Stasiun Buatan

\section{Analisis Keseimbangan Air}

Keseimbangan air memiliki kegunaan untuk mengetahui kondisi air pada surplus dan defisit dapat mengantisipasi bencana yang kemungkinan terjadi, serta dapat pula untuk mendayagunakan air sebaik-baiknya. Persamaan yang dapat digunakan untuk perhitungan neraca air adalah sebagai berikut : Neraca Air $=$ Ketersediaan Air - Kebutuhan Air (5)

Analisis keseimbangan air dilakukan dengan mencari selisih antara hasil analisis ketersediaan dan analisis kebutuhan air. Ketersedian air adalah prediksi tinggi muka air tanah dan kebutuhan air adalah sesuai dengan regulasi pemerintah yaitu $0,4 \mathrm{~m}$ di bawah permukaan tanah.

\section{Analisis Keseimbangan Air Skenario Kondisi Eksisting}

Analisis skenario kondisi eksisting adalah analisis keseimbangan air dengan tidak ada intervensi. Analisis keseimbangan air skenario kondisi eksisting tanpa ada pengaruh tanaman dapat dilihat pada Gambar 9 .

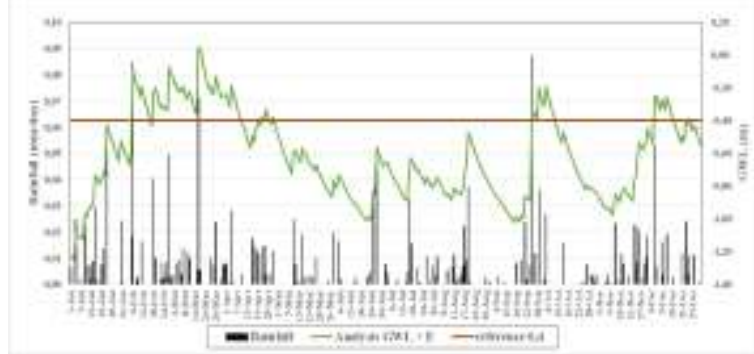

Gambar 9. Analisis Keseimbangan Air Skenario Kondisi Eksisting pada Lahan TORA HGU 09

Pada Gambar 7 disajikan analisis ketersediaan air selama 1 tahun yang terdapat curah hujan, nilai tinggi muka air tanah referensi dan nilai tinggi muka air tanah. Berdasarkan analisis tersebut terjadi tinggi muka air tanah 
diatas tinggi muka air tanah regulasi pemerintah yaitu $-0,4$ m pada periode Februari, Maret, April, Oktober dan Desember yang berarti bahwa ketersediaan air surplus. Selanjutnya, pada bulan Januari, Mei, Juni, Juli, Agustus September dan November curah hujan menurun sehingga terjadi penurunan muka air tanah di bawah tinggi muka air tanah referensi yang diartikan bahwa terjadinya defisit.

\section{Analisis Keseimbangan Air Skenario Tanaman Pertanian}

Analisis keseimbangan air skenario tanaman perkebunan yaitu sagu, kelapa, pinang, aren, dan kopi. Nilai analisis keseimbangan air pada tanaman perkebunan menggunakan asumsi dengan nilai koefisien tanaman adalah sebesar 1,3 dengan pendekatan hujan tahunan. Nilai analisis keseimbangan air pada tanaman sagu, kelapa, pianang, aren dan kopi dapat dilihat pada Gambar 10 .

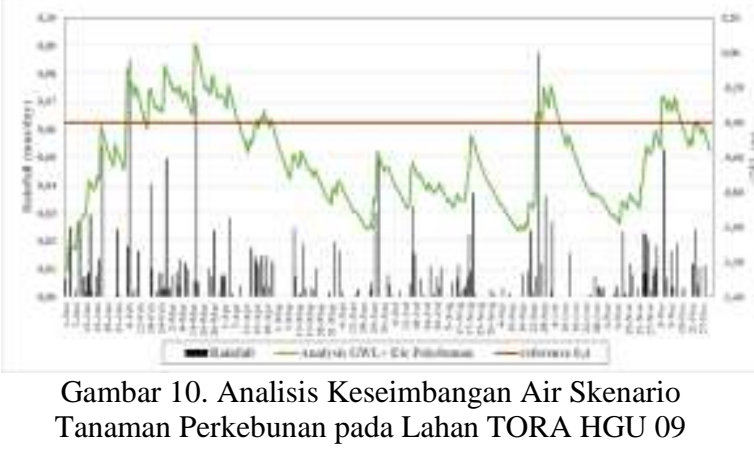

Pada Gambar 8 disajikan analisis ketersediaan air selama 1 tahun yang terdapat curah hujan, nilai tinggi muka air tanah referensi dan nilai tinggi muka air tanah. Berdasarkan analisis tersebut terjadi tinggi muka air tanah diatas tinggi muka air tanah regulasi pemerintah yaitu -0,4 m pada periode Februari, Maret, April, Oktober dan Desember yang berarti bahwa ketersediaan air surplus. Pada analisis keseimbangan air skenario tanaman pertanian ini jika dibandingkan dengan analisis keseimbangan air kondisi eksisting terdapat penurunan tinggi muka air tanah karena pengaruh tanaman pertanian adalah sebesar $0,034 \%$

\section{Analisis Keseimbangan Air Skenario Tanaman Perkebunan}

Analisis keseimbangan air skenario tanaman perkebunan yaitu sagu, kelapa, pinang, aren, dan kopi. Nilai analisis keseimbangan air pada tanaman perkebunan menggunakan asumsi dengan nilai koefisien tanaman adalah sebesar 1,3 dengan pendekatan hujan tahunan. Nilai analisis keseimbangan air pada tanaman sagu, kelapa, pianang, aren dan kopi dapat dilihat pada Gambar 11.

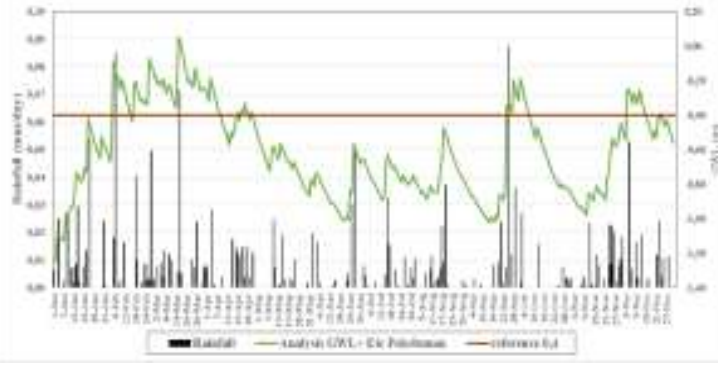

Gambar 11. Analisis Keseimbangan Air Skenario

Tanaman Perkebunan pada Lahan TORA HGU 09

Pada Gambar 11 disajikan analisis ketersediaan air selama 1 tahun yang terdapat curah hujan, nilai tinggi muka air tanah referensi dan nilai tinggi muka air tanah. Berdasarkan analisis tersebut terjadi tinggi muka air tanah diatas tinggi muka air tanah regulasi pemerintah yaitu 0,4 $\mathrm{m}$ pada periode Februari, Maret, April, Oktober dan Desember yang berarti bahwa ketersediaan air surplus. Pada analisis keseimbangan air skenario tanaman perkebunan ini jika dibandingkan dengan analisis keseimbangan air kondisi eksisting penurunan tinggi muka air tanah karena pengaruh tanaman pertanian adalah sebesar $0,101 \%$.

\section{KESIMPULAN}

Pada hasil analisis keseimbangan air skenario kondisi eksisting mengalami defisit pada bulan Januari, Mei, Juni, Juli, Agustus September dan November yang artinya tinggi muka air tanah di bawah regulasi pemerintah yaitu $0,4 \mathrm{~m}$. Keseimbangan air skenario tanaman pertanian dan perkebunan dibandingkan dengan analisis keseimbangan air kondisi eksisting terdapat penurunan tinggi muka air tanah karena pengaruh kebutuhan air tanaman pertanian serta perkebunan secara berurut adalah sebesar 0,034\% dan $0,101 \%$. Alternatif komoditi padi sawah tadah hujan, jagung, nenas, ubi kayu, sagu, kelapa, pianang, aren dan kopi dapat hidup sesuai dengan regulasi pemerintah jika ditanam pada bulan surplus yaitu pada periode bulan Februari, Maret, April, Oktober, dan Desember.

Adapun saran yang diberikan berdasarkan hasil perhitungan dan analisis pada pengerjaan tugas akhir ini antara lain perlu diadakannya manajemen air untuk mencegah kekurangan air pada bulan-bulan defisit air dengan pembangunan sekat kanal.

\section{DAFTAR PUSTAKA}

[1] Kustituanto, B., \& Badrudin, R. (1994). STATISTIKA 1: Deskriptif. Gunadarma

[2] Peraturan Pemerintah RI Nomor 57 Tahun 2016. (2016). Peraturan Pemerintah Republik Indonesia Nomor 57 Tahun 2016 Tentang Perubahan Atas Peraturan Pemerintah Nomor 71 Tahun 2014 Tentang Perlindungan dan Pengelolaan Ekosistem Gambut. 
[3] Sekretariat Kabinet Republik Indonesia. (2018). Presidential Regulation 862018 tentang Reforma Agraria. (1), 1-28. Retrieved from https://sipuu.setkab.go.id/PUUdoc/175620/Perp res Nomor 86 Tahun 2018.pdf.

[4] Soesanto, B., \& Ernanda, H. (1991). Pengantar Hidrologi. Fakultas Pertanian Universitas Jember, Jember.

[5] Takahasi, H., Shigenaga, Y., Hamada, Y., Ebiko, J., \& Setiadi , B. (2017). Monitoring and forecast of groundwater level in tropical peatland and a rice field. SESAME Team for restoration of tropical peatlands. Purwakarta. 